Vol. 11 (2): 269-276 (2021)

\title{
PHOTOCATALYTIC DEGRADATION OF METHYLENE BLUE: A REVIEW ON MODIFIED TITANIUM DIOXIDE
}

\author{
Hilal Kivrak ${ }^{1,2 *}$, Dunya Ibrahim Saleh ${ }^{2}$ \\ $1^{*}$ Eskisehir Osmangazi University, Faculty of Engineering and Architectural Sciences, Department of Chemical \\ Engineering, Eskişehir, 26040 Turkey; \\ ${ }^{2 *}$ Van Yuzuncu Yil University, Faculty of Engineering, Department of Chemical Engineering, Van,65000 Turkey; \\ *Corresponding Author Hilal Kivrak, e-mail: hilalkivrak@gmail.com; hilaldemir.kivrak@ogu.edu.tr;
}

Received January 2021; Accepted February 2021; Published March 2021;

DOI: https://doi.org/10.31407/ijees11.211

\begin{abstract}
Water pollution is increasing through the whole world and various industries are discharging their untreated effluents into the nearby water resources at a great extent. Hence, wastewater treatment with an alternative technology is vital and thus, Advanced Oxidation Process with green chemical approach as photocatalysis has emerged. This review deals with photocatalytic degradation of methylene blue on modified $\mathrm{TiO}_{2}$. Firstly detailed information about photocatalytic properties of $\mathrm{TiO}_{2}$ is given and then various literature studies for methylene blue degradation is reported.
\end{abstract}

Keywords: waste water, $\mathrm{TiO}_{2}$, methylene blue, advance oxidation process, photocatalysis 